\title{
What matters to people aged 80 and over regarding ambulatory care? A systematic review and meta-synthesis of qualitative studies
}

\author{
Angélique Herrler ${ }^{1} \mathbb{D} \cdot$ Helena Kukla $^{1}$ (D) $\cdot$ Vera Vennedey $^{2}$ (D) Stephanie Stock ${ }^{2} \mathbb{D}$
}

Accepted: 8 June 2021 / Published online: 21 August 2021

(c) The Author(s) 2021

\begin{abstract}
The growing percentage of the population aged 80 and over is challenging for healthcare systems, as frailty and other complex health issues are common in this age group. In order to provide patient-centered ambulatory healthcare, their preferences and expectations need to be explored. Therefore, the aim of this study was to systematically search for and synthesize qualitative evidence on how people aged 80 and over believe ambulatory healthcare (medical and nursing care) should be delivered to them. Medline, PsycINFO, CINAHL, Web of Science Core Collection and Google Scholar were searched for full research reports of qualitative studies focusing on the preferences, wishes, needs, expectations and experiences of people aged 80 and over regarding ambulatory medical and nursing care. The results were screened by two independent reviewers using a two-step approach. The included studies were meta-synthesized using Thomas and Harden's 'thematic synthesis' approach in order to gain a new, second-order interpretation of the findings of the primary studies. In the intermediate synthesis step, 14 aspects of healthcare structures and care relationships were identified as relevant. Based on these, three underlying wishes were found: feeling safe, feeling like a meaningful human being, and maintaining control and independence. The results of this review are in line with other research, such as reviews focusing on the preferences of the younger age group (65-80). However, the importance of aspects of care relationships as an integral part of favorable ambulatory healthcare and the wish to be strengthened as a meaningful human being are emphasized more strongly.
\end{abstract}

Keywords Aged · 80 and over · Patient-centered care - Ambulatory care - Qualitative research · Patient preferences · Systematic review

\section{Introduction}

The United Nations (2019) estimate that by 2050, the number of people aged 80 and over will triple to 143 million globally. For these people, the "oldest old," an important aspiration is ageing in place. This means to enable older people to continue living in their home and known environment with as low dependency levels as possible and therefore,

Responsible Editor: Morten Wahrendorf

Angélique Herrler

angelique.herrler@uni-koeln.de

1 Faculty of Human Sciences and Faculty of Medicine, Graduate School GROW, Gerontological Research on Well-being, University of Cologne, Albertus-Magnus-Platz, 50923 Cologne, Germany

2 Institute for Health Economics and Clinical Epidemiology, University Hospital Cologne, 50924 Cologne, Germany avoid institutionalization and transition to a nursing home (Houben 2001). Older people show a preference for ageing in place to maintain their relationships and autonomy (Costa-Font et al. 2009; WHO 2015b; Wiles et al. 2012).

However, this is particularly challenging due to healthrelated impairments (Betini et al. 2017; Hajek et al. 2015). Although the effects of ageing vary between individuals, research conducted in recent years indicates a considerable deterioration in physical health status among very old people. In addition to higher multimorbidity among this age group, frailty becomes increasingly common (Collard et al. 2012; Marengoni et al. 2011; Rockwood et al. 2011; Rosero-Bixby and Dow 2009). Frailty, a state of general vulnerability, is the result of decreased capacities in different body systems interacting (Fried et al. 2004; WHO 2015b). It increases the risk of further geriatric syndromes that are highly prevalent from the age of 80 , such as falls and urinary incontinence (Inouye et al. 2007; WHO 2015b). Subsequently, these older people need help with one or more 
aspects of daily life, and are frequent users of the healthcare system (Marengoni et al. 2011; van den Bussche et al. 2011; WHO 2015b).

Since a considerable proportion of the ageing population's health issues are complex and chronic in nature, the purpose of healthcare services is expected to shift from acute care and curing toward (1) chronic care and (2) individualized goals and encouraging active involvement of patients. There are two major propositions for reorienting healthcare to address this shift. The first proposition is a stronger focus on ambulatory care, i.e., the provision of a broad range of healthcare services including prevention, curation and rehabilitation on an outpatient basis (Berman 2000). Ambulatory care is of particular importance for ageing in place and considered to best manage the requirements of complex and chronic care, especially regarding timely access, care coordination and cost-efficiency (WHO 2015a). Secondly, models of patient-centered care (PCC) are frequently proposed to encourage individualized care, and are now being called for by important international organizations such as the World Health Organization (2015b). In contrast to episode-based clinical care, where patients are rather passive, the core of these models is to actively involve patients and incorporate their individual values, needs and preferences (Lusk and Fater 2013; Scholl et al. 2014). As such, in order to bring healthcare systems in line with the demographic shift, older people's subjective needs and preferences, especially regarding ambulatory care, should be explored and used as the basis for adaptations.

Previous approaches to examining older people's healthcare needs and preferences have focused mainly on the 60 and over age group. Although people aged 80 and over were not excluded in these reviews, most participants were below 80 years of age (Gonzalez et al. 2019; Gregory et al. 2017; Holm et al. 2013; McGilton et al. 2018). Therefore, the results may not be representative for the oldest-old, especially regarding their special health issues as mentioned above. Furthermore, previous studies have focused on institutional settings such as hospitals and nursing homes (Bridges et al. 2010; Maurer et al. 2019). This issue was addressed by a recent scoping review that focused on home environments, but only included studies on home healthcare recipients (Dostálová et al. 2020). As such, the variety of healthcare needs and preferences, including those for older people who are in good enough health to manage on their own or with help of relatives in the ambulatory setting, remains unclear. To fill this research gap, a broader systematic review covering the subjective perspective of people aged 80 and over regarding ambulatory care is needed. Thus, the aim of this study was to synthesize qualitative evidence on the design of ambulatory care as desired by people aged 80 and over. The overall research question was: What matters to people aged 80 and over regarding ambulatory care?

\section{Methods}

A systematic literature search and a thematic synthesis of the findings were conducted in order to provide a metasynthesis. Qualitative meta-synthesis aims to transform the findings into integrated descriptions and explanations of the qualitative research phenomenon (Sandelowski and Barroso 2007). For this review, Thomas and Harden's (2008) inductive "thematic synthesis" approach that focuses on the integration of individual experiences and perspectives was applied.

The review was prospectively registered at PROSPERO (record number: CRD42020158107). Reporting is based on the Preferred Reporting Items for Systematic Reviews and Meta-Analyses (PRISMA, Moher et al. 2009) and the Enhancing Transparency in Reporting the Synthesis of Qualitative Research statement (ENTREQ, Tong et al. 2012).

\section{Search strategy}

In order to develop the search strategy, the following review question was formulated based on the overall research question: What are the preferences, needs and expectations of the oldest-old regarding ambulatory care, from their perspective? Since these terms are often used inconsistently or interchangeably in qualitative studies on healthcare structures, they were found to be appropriate to represent "what patients want from their healthcare" following Street et al. (2012, p. 168). Combined search terms and controlled vocabulary relating to people aged 80 and over, preferences and ambulatory medical and nursing care were used. The search was limited to qualitative studies because the area of interest was the subjective perspective of the older persons. The search strategy was piloted in PubMed, together with the inclusion criteria. The final strategy (Online Resource 1) was adapted to the other databases.

The first author searched electronic bibliographic databases related to medicine and health sciences (Medline via PubMed, PsycINFO, CINAHL, Web of Science Core Collection) for full primary research reports from inception to October 2019. A search in Google Scholar and a forward and backward citation search of included studies were also conducted. Research reported in English, German and Dutch was included. A search update was carried out in September 2020, but no recent studies were eligible for inclusion. The retrieved results were merged into the citation management software EndNote X9 (Clarivate Analytics, Boston). 


\section{Selection of studies}

Studies were screened using a two-step approach: firstly, two authors (AH, HK) independently screened all the abstracts for eligibility. Unclear cases were discussed until consensus was reached. Secondly, the full texts of the included abstracts were assessed for inclusion. In case of disagreement, a third reviewer (VV) was consulted in order to reach consensus. The authors of studies with missing information (e.g., regarding the sample's age structure) were contacted.

Qualitative studies in which people aged 80 and over (median or average age of study population: at least 80 years) who live at home expressed their views were eligible for inclusion. In addition to studies reporting directly on care preferences, needs and expectations, studies on participants' positive and negative care experiences were also included, because it was expected that preferences would be derived from these descriptions. Studies on end-of-life care were excluded, since the goals of this can differ strongly from other areas of (geriatric) care. The search and selection criteria are summarized in Table 1.

\section{Quality appraisal}

Two authors (AH, HK) independently evaluated the quality of each included study. Since our aim was to synthesize the qualitative studies' findings and provide a second-order interpretation, we were especially reliant on their validity, meaning that the findings are reasonable representations of the original data and their contexts, and are convincing and coherent (Leung 2015; Whittemore et al. 2001). This means that data, data collection and analysis had to be appropriate to the respective qualitative research aim (Leung 2015). Therefore, we used the Quality Appraisal Checklist for Qualitative Studies of the National Institute for Health and Care Excellence that examines the appropriateness and coherence of the study instead of item reporting (NICE 2012). Unclear cases were discussed with a third reviewer (VV) where necessary. Quality appraisal was used not to weight individual study contributions, but to evaluate the robustness of the synthesized findings.

\section{Analysis and synthesis}

The results of the included studies formed the basis for the synthesis. In studies reporting on different participant groups, only those parts explicitly referring to the perspective of people aged 80 and over were used. The analysis was conducted using MAXQDA Analytics Pro 2020 (VERBI software, Berlin). In accordance with Thomas and Harden (2008), the analysis consisted of three steps: inductive lineby-line-coding, development of descriptive themes, and development of analytical themes (integration and explanation of the findings).

Table 1 Search and selection criteria

\begin{tabular}{|c|c|c|}
\hline & Inclusion & Exclusion \\
\hline Population & $\begin{array}{l}\text { - Participants aged } 80 \text { or older } \\
\text { - Mean age or median age of study population is } 80 \text { or } \\
\text { older } \\
\text { - Mixed participant groups: inclusion, if results for peo- } \\
\text { ple aged } 80 \text { or older can be separated }\end{array}$ & $\begin{array}{l}\text { - Mean age or median age is under } 80 \text { years } \\
\text { - Mixed participant groups: exclusion, if results are mixed } \\
\text { and cannot be separated for people aged } 80 \text { and older }\end{array}$ \\
\hline Phenomenon of interest & $\begin{array}{l}\text { - Studies on preferences, wishes and needs of older } \\
\text { people regarding formal/professional medical or nurs- } \\
\text { ing care } \\
\text { - Studies on care experiences, problems, determinants } \\
\text { and factors of care regarding formal/professional } \\
\text { healthcare }\end{array}$ & $\begin{array}{l}\text { - Studies on end of life care, particular therapies } \\
\text { - Studies on technical devices and applications } \\
\text { - Studies not focusing on healthcare } \\
\text { - Studies on informal/unprofessional care or volunteer } \\
\text { work }\end{array}$ \\
\hline Context/Setting & $\begin{array}{l}\text { - Ambulatory/outpatient healthcare (medical and nursing } \\
\text { care) } \\
\text { - Primary healthcare, general practice } \\
\text { - Home healthcare } \\
\text { - Participants living at home }\end{array}$ & $\begin{array}{l}\text { - Participants living in an institutional care setting } \\
\text { - Hospital care }\end{array}$ \\
\hline Study design & $\begin{array}{l}\text { Qualitative studies focusing on the perspective and } \\
\text { descriptions of older people (interviews, focus groups, } \\
\text { group interviews with semi-structured interview guides } \\
\text { or open-ended questions) }\end{array}$ & $\begin{array}{l}\text { - Non-qualitative study designs } \\
\text { - Studies not focusing on the own perspective and descrip- } \\
\text { tions of older people, e.g., surveys, observations } \\
\text { - Mixed-methods designs in which qualitative findings of } \\
\text { older people's perspectives cannot be separated }\end{array}$ \\
\hline Language & English, German, Dutch & Other languages \\
\hline Type of research report & Full research reports & $\begin{array}{l}\text { Poster abstracts, editorials, comments, book chapters, study } \\
\text { protocols }\end{array}$ \\
\hline
\end{tabular}


Firstly, the findings of the primary studies were inductively coded line-by-line with regard to their content and meaning. Two authors (AH, HK) independently coded a random sample of four studies. Secondly, both authors categorized them toward an initial set of descriptive themes and discussed their results for consensus. Subsequently, the independently examined eight and nine descriptive themes were refined to a set of ten that described relevant aspects of two dimensions: healthcare structures and care relationships. The remaining studies were coded with these themes and in the final consultation, the set was refined to fourteen descriptive themes (Table 2). Moreover, first ideas to explain the themes were collected during this process.

Thirdly, the similarities and differences in the descriptions of all the aspects were compared theme-by-theme in order to gain an understanding of why they matter to older people and develop saturated analytical themes. Since we were not working with primary data and therefore, could not rely on a concept of saturation based on the emergence of new codes and potentially conducting more interviews, we built on a concept of meaning saturation and the explanatory power of the analytical themes (Hennink et al. 2017; Saunders et al. 2018). This meant that we did not stop analysis at the point of information redundancy but at the point of the best fit between our primary studies' findings and the analytical themes. Therefore, one author $(\mathrm{AH})$ compared the themes and suggested a set of analytical themes that best integrated and explained them based on the earlier collection of ideas. In the next step, this was discussed in the research team and the analytical themes were refined. The two steps were repeated and after the next revision, the second author checked the results regarding the analytical themes to validate them. After this step, minor revisions regarding the analytical themes' wording were conducted and a final discussion with the research team took place that confirmed the analytical themes. While the descriptive themes describe general relevant care aspects, the analytical themes were ultimately understood as the underlying wishes of older people that explained why these aspects are relevant, and what matters to them fundamentally regarding ambulatory care.

\section{Results}

\section{Systematic review and quality appraisal}

In total, 5576 research reports were identified during the search process. A flowchart for the search and selection process is provided in Fig. 1. Following screening for eligibility, 23 full texts were included for quality appraisal (22 peerreviewed articles, 1 doctoral thesis). During this step, the article by Krothe (1997) was excluded because her doctoral thesis on the same study sample was also retrieved, and demonstrated higher quality (Online Resource 2). Ultimately, 22 studies were included for meta-synthesis.

\section{Characteristics of included studies}

Most of the included studies were conducted in Northern and Western Europe $(n=15)$, and used interviews for data collection $(n=19)$. The studies comprised 330 eligible older participants in total, approximately two thirds of whom were female. Eight studies assessed the participants' views regarding home care and community-based long-term care, six studies dealt with ambulatory general practice or specialist care. Moreover, three studies examined (preventive) home visits and case management, respectively. While two studies reported that most of their participants perceived their health status to be reasonable to excellent and another two studies focused on dementia patients, the rest of the included studies reported on older people with several varying chronic conditions, multimorbidity, frailty or at risk for functional decline and institutionalization. Therefore, most of the studies did not examine a specific or acute occasion for seeking care, but the older people's general experiences with care they received for long-term conditions and related impairments. An overview of the studies' characteristics is provided in Table 3 .

\section{Results of meta-synthesis}

We identified three analytical themes as the underlying wishes of older people: (1) feeling safe, (2) feeling like a meaningful human being and (3) maintaining control and independence (Fig. 2). These appear to be of equal importance and do not follow a hierarchy; instead, they rather interact with and complement each other. Despite the second theme that was not present in the studies on case management, the analytical themes represent the diverse range of ambulatory care settings and health conditions of older people as described above. Therefore, the three themes should be understood as set of general underlying wishes of older people regarding ambulatory healthcare structures and care relationships rather than regarding specific treatments or care settings. As the core of the meta-synthesis, the three analytical themes/wishes are described in detail in the following section and complemented by their most significant relations to single care aspects as found in this review.

\section{Feeling safe}

The first fundamental wish was "feeling safe." Older people had several fears related to their age (e.g., medical emergencies, consequences of polypharmacy, further physical or mental deterioration) that evoked a strong 


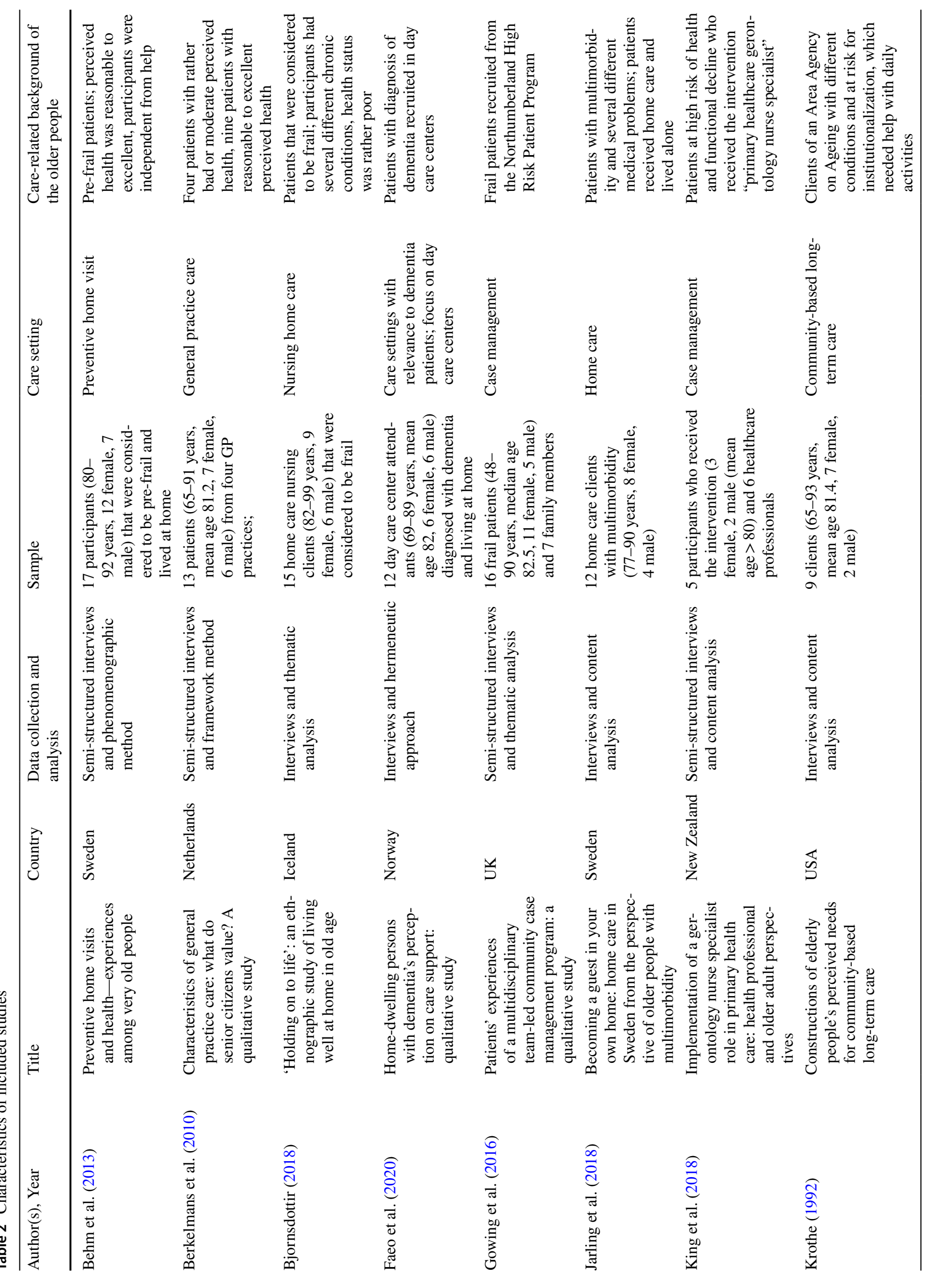




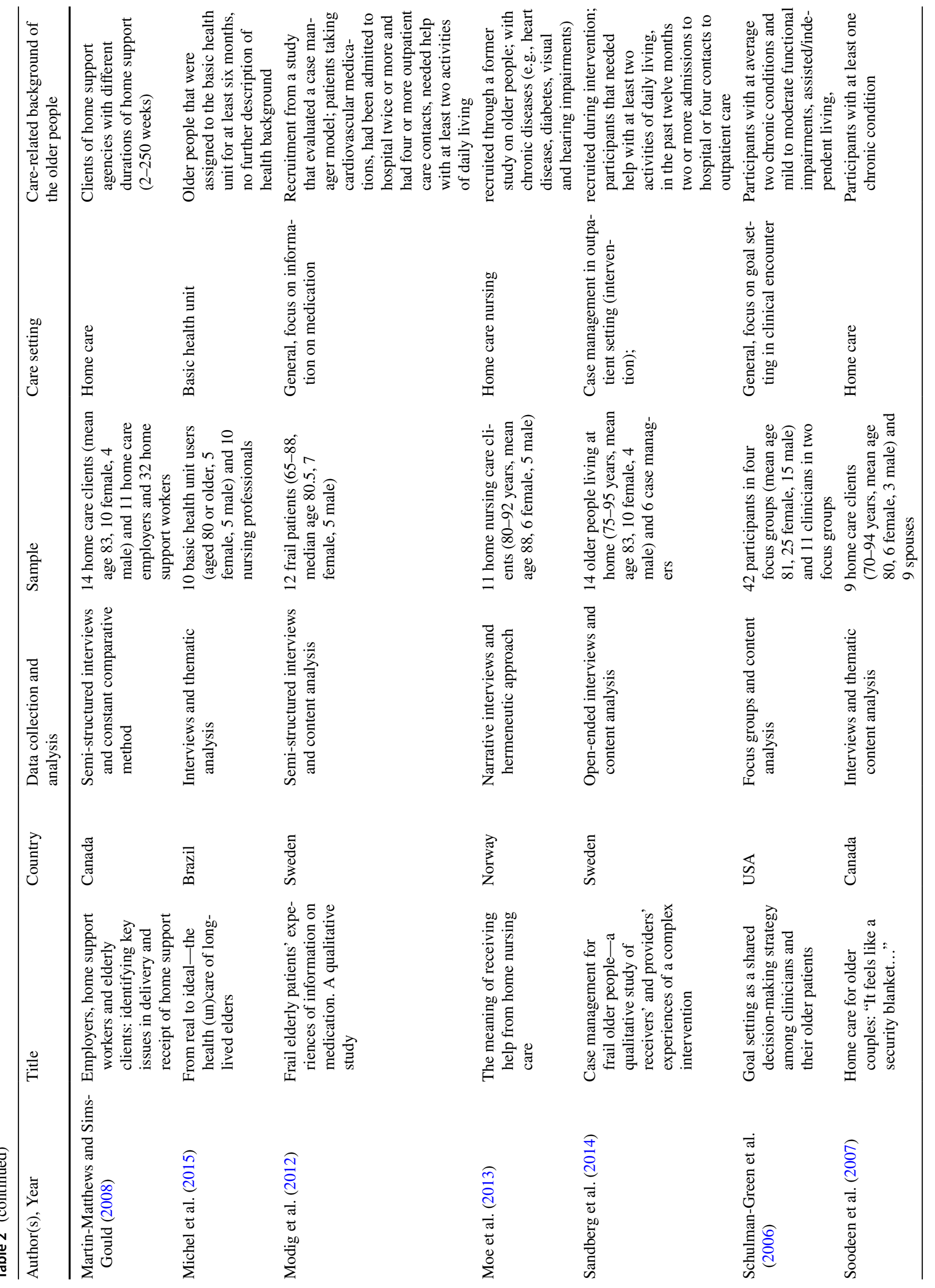




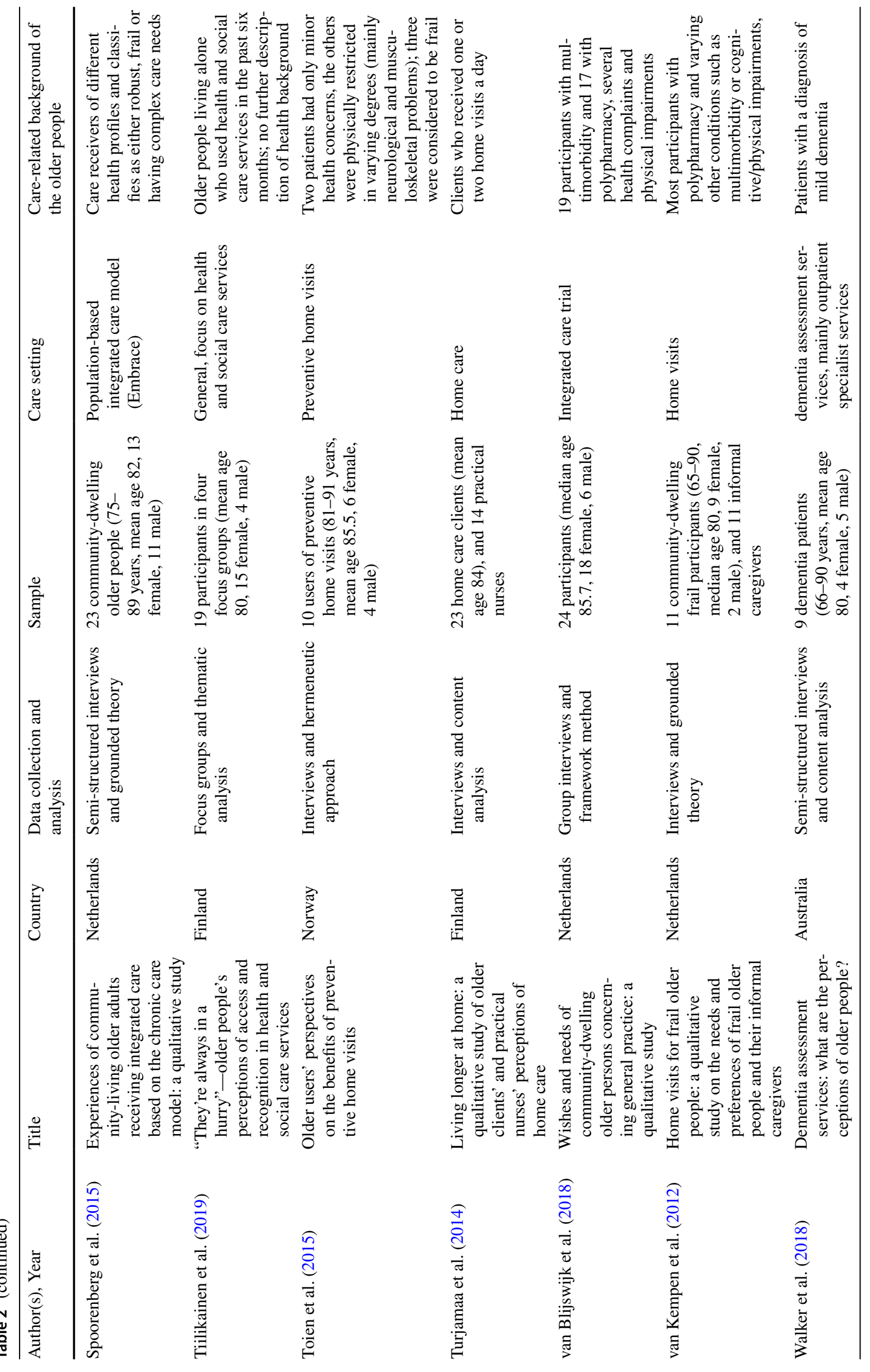




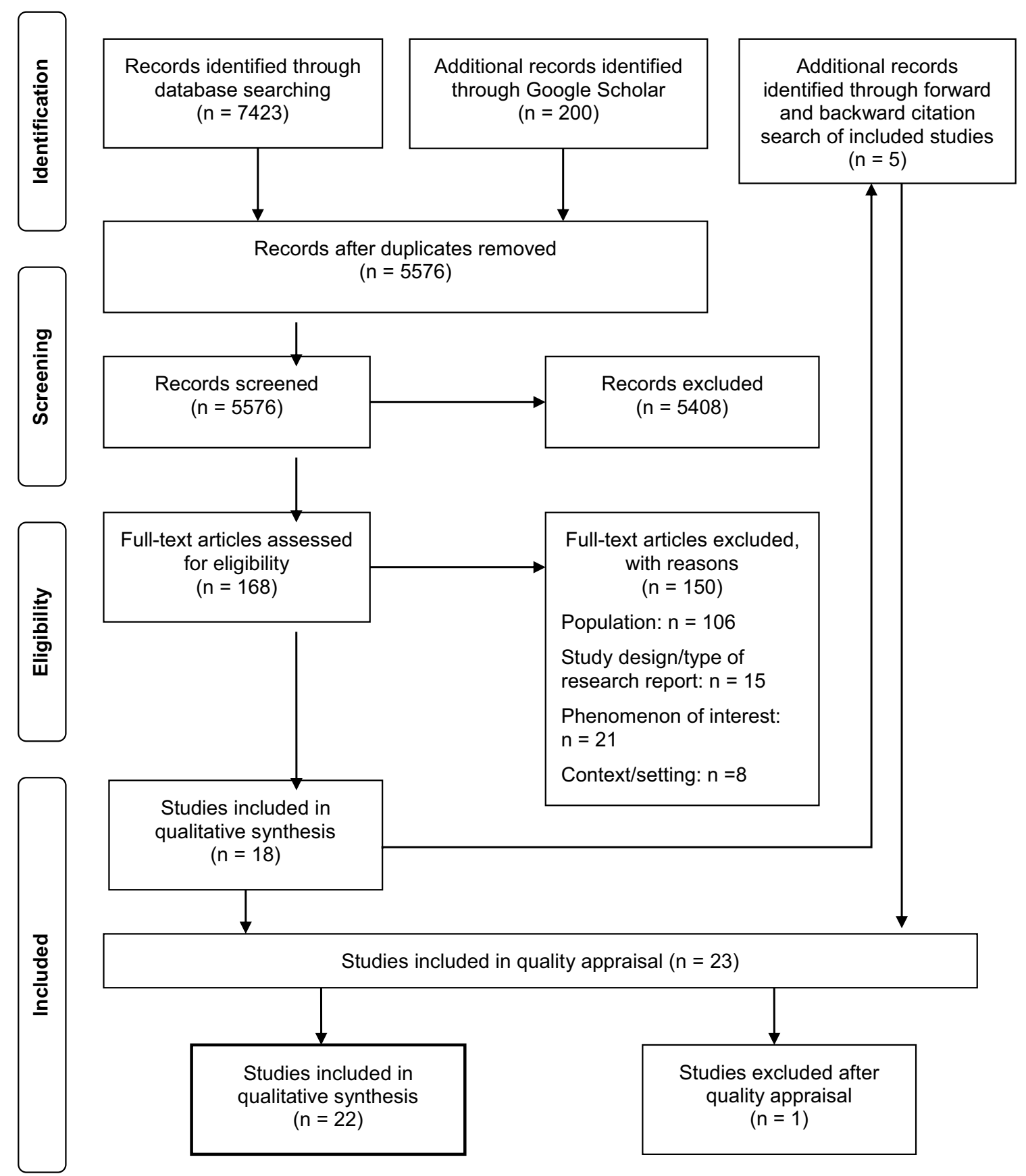

Fig. 1 Identification and selection of studies for meta-synthesis based on PRISMA statement

desire for a "safety net" regarding their healthcare and daily life (Behm et al. 2013; Berkelmans et al. 2010; Faeo et al. 2020; Gowing et al. 2016; Jarling et al. 2018; Modig et al. 2012; Moe et al. 2013; Sandberg et al. 2014; Soodeen et al. 2007; Spoorenberg et al. 2015; Toien et al. 2015; Turjamaa et al. 2014; Walker et al. 2018). An 82-year-old male participant in Toien et al. (2015) said:
The most important is the safety-you know, that someone cares and looks after you and checks that the head is still functioning; that is very reassuring. And knowing you are within the municipality's system (p. 704, preventive home visits). 
Table 3 Explanation of descriptive themes

\begin{tabular}{ll}
\hline Descriptive theme & Meaning \\
\hline $\begin{array}{l}\text { Healthcare structures } \\
\text { Time for care }\end{array}$ & Time that is available for appointments, interactions and care in general \\
Skills of professionals & Knowledge, technical and communication competencies of healthcare professionals \\
Sufficient support & Care that is suitable to support the older person with its individual needs \\
Care coordination & Care that is organized and supervised by a healthcare professional \\
Access to care & Fast and easy availability of different care services, e.g., specialist care \\
Continuity and reliability of care & Care that is predictable and provided by familiar persons \\
Information & Extent, content and manner of information transfer between older person and healthcare professional \\
Place of care & Regular setting in which care is provided (home/ambulatory versus institutional care) \\
Care relationships & \\
Involvement in decisions and care & Role and inclusion of the older person in decision processes and care situations \\
Care contact as social contact & Interactions with care professionals as meaningful social interactions beyond the main reason for care \\
Friendliness & Attitude and handling of healthcare professionals toward older people \\
Personal care relationships & Close and trustful relationships between the older person and healthcare professionals \\
Activation & Motivation and support for the older person to participate in activities \\
Open and confidential communication & Atmosphere that allows older people to speak uninhibitedly and bring up their problems \\
\hline
\end{tabular}

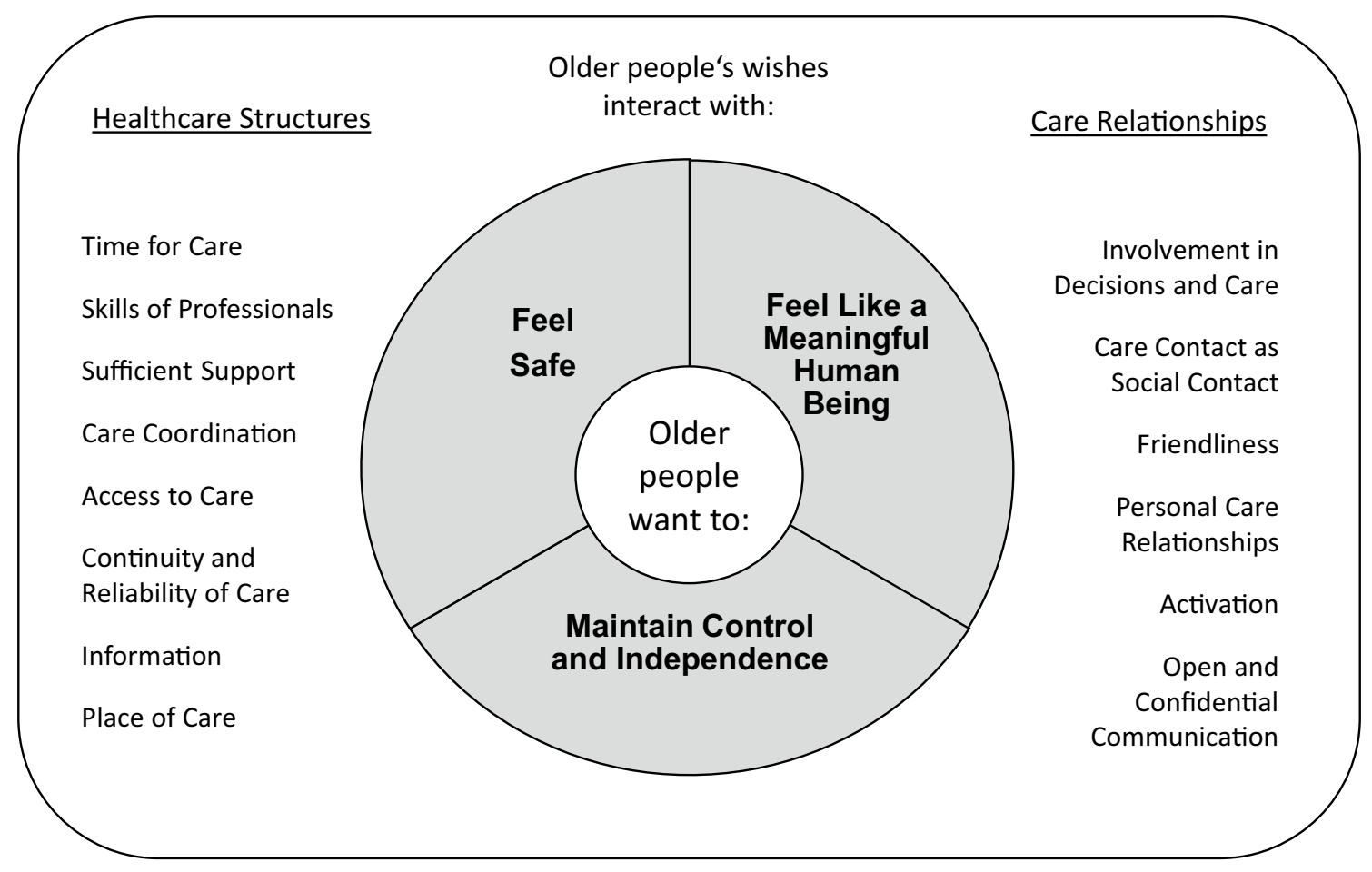

Fig. 2 Results of the meta-synthesis. Analytical themes represent underlying wishes (center), descriptive themes represent relevant aspects of healthcare structures (left) and care relationships (right)

The strongest contributions to a sense of security among older people were found in aspects of the healthcare structures. Older people felt safe when they received the support they considered necessary, i.e., sufficient, attentive care that met their needs and included individual adjustments (Bjornsdottir 2018; Modig et al. 2012; Soodeen et al. 2007; Toien et al. 2015). The feeling of safety was particularly pronounced when a healthcare professional or case manager monitored their health status and stayed in touch with them (Bjornsdottir 2018; Faeo et al. 2020; Gowing et al. 2016; King et al. 2018; Sandberg et al. 2014; Spoorenberg et al. 2015; Toien et al. 2015; van Blijswijk 
et al. 2018). Conversely, participants felt insecure when they did not receive the support they needed (Gowing et al. 2016; Modig et al. 2012). In addition to this, continuous, reliable and predictable care was important to the feeling of safety, while participants feared a high turnover of healthcare professionals (Berkelmans et al. 2010; Bjornsdottir 2018; Jarling et al. 2018; Martin-Matthews and Sims-Gould 2008; Modig et al. 2012; Moe et al. 2013; Spoorenberg et al. 2015).

Another important factor for safety was care coordination. Older people felt relieved and safe when their care was coordinated by a healthcare professional or case manager, i.e., when someone organized their care and ensured collaboration between different healthcare providers (Gowing et al. 2016; King et al. 2018; Sandberg et al. 2014; Spoorenberg et al. 2015; Walker et al. 2018). Sandberg et al. (2014) stated:

[...] case management was experienced as something beneficial and something that could contribute to a sense of security (p. 9, case management).

Moreover, being able to access healthcare (e.g., general practice, specialists) and a familiar contact person quickly and easily when necessary was perceived as essential (Behm et al. 2013; Berkelmans et al. 2010; Moe et al. 2013; Spoorenberg et al. 2015; Toien et al. 2015). Likewise, waiting times and not receiving direct access evoked feelings of insecurity (Berkelmans et al. 2010; Modig et al. 2012). The same applied to information, as shown by a statement in Modig et al. (2012):

If the information was limited and there was no one available to answer questions, there were soon feelings of insecurity (p. 6, information on medication).

Receiving sufficient information regarding their care, such as information on medication, was crucial to helping older people feel safe (Modig et al. 2012; Moe et al. 2013). Information on additional services and care options improved the sense of safety (Behm et al. 2013; Turjamaa et al. 2014), as did experience, knowledge and communication skills on the part of healthcare professionals (Berkelmans et al. 2010; Spoorenberg et al. 2015; Walker et al. 2018).

Other factors important to a sense of safety for older people were found in their care relationships. Close and long-term relationships promoted trust and feelings of safety (King et al. 2018; Sandberg et al. 2014; Soodeen et al. 2007). This was closely linked to open communication; if the communication style between the older persons and their professional caregivers was not confidential and trustful, insecurity and distrust increased (Jarling et al. 2018; Modig et al. 2012).

\section{Feeling like a meaningful human being}

This theme represents the external perception and selfperception of aged persons within care relationships. While most of these people had to deal with physical and mental deteriorations such as diminished vision and, consequently, restrictions such as loss of mobility, they focused on the remaining options available to them - they wanted to enjoy their lives despite their old age (Behm et al. 2013; Bjornsdottir 2018; Faeo et al. 2020; Moe et al. 2013; Spoorenberg et al. 2015). The primary studies showed that older people wanted to be seen and accepted as valuable individuals who still act on their own, take pleasure in daily activities and contribute something to society (Behm et al. 2013; Krothe 1992; Martin-Matthews and Sims-Gould 2008; Moe et al. 2013; Tiilikainen et al. 2019; Toien et al. 2015). This was described as being "confirmed [...] as a human being" (Moe et al. 2013, p. 744) and "a wish for dignity, value, and selfesteem" (Toien et al. 2015), p. 706). As one 82-year-old woman in the interviews in Toien et al. (2015) put it:

That I am not just sitting here and am forgotten, but that someone makes me feel that I still have something to contribute. That I'm not just a weak human being who sits here, but I still mean something (p. 707, preventive home visits).

However, the studies revealed that older people endured a variety of negative care experiences. Depending on their interaction with their caregivers, they described feeling unimportant, worthless, vulnerable, helpless, overlooked or inferior, and said they were afforded lower priority and interest because of their age (Behm et al. 2013; Bjornsdottir 2018; Jarling et al. 2018; Modig et al. 2012; Moe et al. 2013; Tiilikainen et al. 2019). This was connected to a loss of privacy (in home care) and feeling like a burden to others (Jarling et al. 2018; Moe et al. 2013; Tiilikainen et al. 2019).

In view of this, it was not surprising that whether an older person felt like a meaningful human being was strongly connected to their care relationships. The most important aspect of this was social contact itself, i.e., conversations and interest toward the older people (Behm et al. 2013; Jarling et al. 2018; Krothe 1992; Moe et al. 2013; Soodeen et al. 2007; Tiilikainen et al. 2019). Soodeen et al. (2007) summarized:

[...] becoming acquainted with their [healthcare worker] beyond interacting about the tasks at hand and enjoying a little casual conversation help[ed] put the [care receivers] at ease (p. 1249, home care).

More explicitly, experiencing friendliness and respect made older people feel valuable, while experiencing rudeness and disrespect made them feel burdensome and unimportant (Bjornsdottir 2018; Jarling et al. 2018; Moe et al. 2013; Soodeen et al. 2007; Toien et al. 2015). Such negative care 
relationship experiences inhibited open communication between the older persons and their healthcare providers (Jarling et al. 2018; Moe et al. 2013). Furthermore, receiving the support they needed promoted a sense of meaningfulness among older people. Individual help enabled them to continue doing things they considered important, and therefore improved their well-being (Moe et al. 2013; Tiilikainen et al. 2019; Toien et al. 2015).

\section{Maintaining control and independence}

The third fundamental wish identified by the older people was to maintain their control and independence. This related to several aspects of their healthcare structures and care relationships. It became apparent that participants adapted to age-related changes on their own, for instance by giving up certain activities, and that they tried to manage as many things as they could on their own (Behm et al. 2013; Bjornsdottir 2018; Krothe 1992; Michel et al. 2015; Modig et al. 2012; Sandberg et al. 2014; Soodeen et al. 2007). A participant in Soodeen et al. (2007) explained:

You've got more self-worth, you know, thinking, 'well, I can do it for myself yet' (p. 1247, home care).

This illustrates the wish to be independent, and that older people wanted to avoid receiving care and support for as long as possible, because they feared losing control (Behm et al. 2013; Berkelmans et al. 2010; Bjornsdottir 2018; Faeo et al. 2020; Krothe 1992; Sandberg et al. 2014; Spoorenberg et al. 2015; Tiilikainen et al. 2019; van Kempen et al. 2012). Being independent was important to their sense of control and their self-esteem — but they also acknowledged that they needed help to maintain their independence (Behm et al. 2013; Bjornsdottir 2018; Faeo et al. 2020; Gowing et al. 2016; Krothe 1992; Soodeen et al. 2007; Toien et al. 2015).

On the other hand, anecdotes frequently stated that receiving support, such as home care, meant adapting to caregivers' work routines and schedules, and loss of control, influence and choices, culminating in feelings of dependence and exposure (Gowing et al. 2016; Jarling et al. 2018; Krothe 1992; Moe et al. 2013; Soodeen et al. 2007; Spoorenberg et al. 2015; Tiilikainen et al. 2019; Toien et al. 2015). A female participant in the interviews of Jarling et al. (2018) reported:

I have said, no guys, when I shower... don't want to show myself when I am old. I feel ashamed. Shame, you're ashamed... for your body when it becomes old. Those who send me caregivers do not take my privacy into account (p. 4, home care).

It became clear that maintaining control and independence was a delicate balancing act. This proved once more that receiving the support they needed was crucial to older people. Receiving too little or too much support could lead to dependence, whereas the "right" amount of support, i.e., an individually adjusted program, promoted feelings of selfcontrol and independence among older people (Gowing et al. 2016; Krothe 1992; Sandberg et al. 2014). For most older persons, this was only possible at home; institutional care was perceived as a threat to their self-control and independence (Bjornsdottir 2018; Gowing et al. 2016; Jarling et al. 2018; Krothe 1992; Soodeen et al. 2007; Spoorenberg et al. 2015; van Blijswijk et al. 2018). As such, receiving appropriate information on topics such as additional services that would allow them to continue living at home and healthcare professionals who were willing to share their knowledge were important aspects of favorable healthcare (Krothe 1992; Michel et al. 2015; Modig et al. 2012; Toien et al. 2015).

In addition to this, the relationships between healthcare professionals and care receivers affected the older people's feeling of independence. A close relationship and open, confidential communication were favorable (Jarling et al. 2018; Krothe 1992; Soodeen et al. 2007). Consequently, being involved in decisions and their care helped older people to feel independent and in control, and to achieve their individual goals (Berkelmans et al. 2010; Gowing et al. 2016; Jarling et al. 2018; Krothe 1992; Modig et al. 2012; Moe et al. 2013; Sandberg et al. 2014; Schulman-Green et al. 2006; Spoorenberg et al. 2015; Tiilikainen et al. 2019; Turjamaa et al. 2014; van Blijswijk et al. 2018). Spoorenberg et al. (2015) stated:

The participants made decisions in cooperation with their case managers, which increased their sense of being in control (p. 12, population-based integrated care/case management).

This was complemented by the promotive effects of (physical, mental, social) activation via healthcare professionals (Behm et al. 2013; Krothe 1992; Martin-Matthews and Sims-Gould 2008; Spoorenberg et al. 2015; Toien et al. 2015; van Blijswijk et al. 2018).

\section{Discussion}

The aim of this review was to explore what matters to people aged 80 and over regarding ambulatory care. The meta-synthesis of 22 qualitative studies showed that three underlying wishes shape older people's perspectives: feeling safe, feeling like a meaningful human being, and maintaining control and independence.

The results are in line with previous meta-studies on the preferences and needs of older people. Dostálová et al. (2020) found six themes in fifteen studies exploring the needs of home care recipients: (1) coping with illness, (2) 
autonomy, (3) relationship with professionals, (4) quality, safe and secure care, (5) role in society, and (6) environment. The authors stated that in the opinion of older people, good care also counteracts loneliness and includes casual conversations with caregivers, whereas a lack of interest in the care recipients was considered poor-quality care. While Dostálová et al. (2020) focused only on home care, this review shows that the themes are similar for ambulatory medical and nursing care in general. This might be an indication that the results truly represent the fundamental motives of the oldest old, which tend to be related to the general circumstances of their age rather than their specific care dependency. However, consequences of the perception of the older persons as meaningful individuals, by both themselves and others, seem to be more central in our review.

There are also similarities with reviews with a lower average sample age. For example, a qualitative meta-study on the needs of older people in community healthcare stressed the role of maintaining self-esteem and health (Holm et al. 2013). Two central themes were reported: (1) "reconciliation with how life has come" and (2) "desire to regain identity and sense of self-worth despite disability" (p. 6). Autonomy and the older person's sense of self were also important in studies on healthcare experiences synthesized by Gregory et al. (2017). In line with this research, our work highlights how professional care and support may be both a threat to individual independence and the key factor in the continuation of said independence. This balancing act is a neverending challenge in older age, although support needs could have been expected to be common and more accepted in this group.

This might be due to a different interpretation of "control" in older age. On this matter, Claassens et al. (2014) conducted a qualitative study to explore the concept of perceived control in healthcare among frail older adults. The authors found that the need for control did not become less important in older age, though it did take a different form. For example, the role of communication and involvement became more important to the perception of control (Claassens et al. 2014). This is in line with our findings on the significance of care relationships and care involvement to the feeling of maintaining control. The concept study also showed healthcare aspects that are able to strengthen older people's feeling of control that we also identified, such as being monitored, care coordination, and trustful relationships (Claassens et al. 2014).

Overall, our findings are similar to meta-studies on the needs and preferences of people aged 65-80, and do not show substantial differences. However, the underlying wishes that were revealed in the meta-synthesis emphasize the social dimension of care more strongly than it is found in functional care structures. This may be due to the fact that older persons need and use healthcare more frequently, so healthcare becomes a significant part of their daily lives (Marengoni et al. 2011; van den Bussche et al. 2011; WHO 2015b). Our review shows that people aged 80 and over generally consider the incorporation of their emotional and social needs during care interactions to be integral to favorable ambulatory care. For those affected by social isolation, these aspects become even more important (Nicholson 2012).

By contrast, care models applied to older people focus mainly on assessment, care coordination and interdisciplinary treatments. Popular examples include the Chronic Care Model (CCM) and the Patient-Centered Medical Home, which are often used as basis for care interventions (Bodenheimer et al. 2002; John et al. 2020). Attempts to adopt the CCM for geriatric care, such as the Geriatric Care Model, take into account more comprehensive assessments and care coordination, which are designed specifically to cater to older people's wish to feel safe (Hoogendijk et al. 2016; Muntinga et al. 2012; Muntinga et al. 2015). However, the importance of personal care relationships and strengthening the older person as a meaningful human being do not seem to be represented sufficiently thus far and should be emphasized more strongly. Our results show that casual conversations, genuine interest in the older person, friendliness and respect promote these goals. As such, referring this demographic to other services such as social welfare, as is often proposed in existing models of care, cannot be seen as a complete solution. Instead, it could be worthwhile to focus on the health professionals' behavior and attitude toward older people and adapt care structures accordingly (e.g., by raising awareness of social needs and providing more time for care).

\section{Strengths and limitations}

To our knowledge, this is the first qualitative meta-synthesis on ambulatory healthcare needs and preferences from the genuine perspective of people aged 80 and over. The chosen search strategy enabled the consideration of a comprehensive research status, and the systematic analysis approach ensured intersubjectively valid, i.e., trustworthy and coherent results. Although the 22 included studies focused on different research questions and aspects of ambulatory healthcare, the results are mostly unambiguous, the core of the final three analytical themes emerged fast in the analysis process and further steps mainly addressed their wording and clarifications of their understanding. Therefore, we assume that the analytical themes provide a reasonable integration and explanation of the primary studies' findings and can be considered saturated in their meaning. Furthermore, the methodological quality of the individual studies was found to be sufficient according to the quality appraisal specifically encompassing trustworthiness, coherence, and 
the appropriateness of the research design; this strengthens the validity of the results.

However, several limitations must be considered. Firstly, there is a possibility of dissemination bias if qualitative studies or parts of their results are not made available in full (Booth et al. 2018). The study sample is also limited by the exclusion of languages other than English, German and Dutch. Additionally, the average age of potentially eligible studies' samples was often unclear, and some authors did not respond to our requests for contact; this resulted in the exclusion of the studies in question. Despite the use of a comprehensive research strategy including an update after one year, further or contradictory research results may not have been considered.

Secondly, the findings are only applicable to developed and high-income countries, since the included studies were conducted in such countries. Primarily due to the lower average sample age, studies from low-income countries had to be excluded during screening. Since there are indications that accessibility and affordability of care are far more important issues for older people in these countries and preferences may differ depending on cultural background and known care structures, caution should be exercised if transferring the results (WHO 2015b). Further studies are needed in the countries not covered by this review, though our results could serve as a basis for their design and analysis.

Thirdly, the studies included do not represent the full range of (medical and nursing) care and services necessary to age in place. Moreover, the evidence from qualitative studies presented in this review hardly covers acute occasions for seeking ambulatory care (e.g., acute exacerbations of a chronic condition) and it is possible that older people's priorities and preferences are different in these care situations. In order to design comprehensive older-peoplecentered care, the perspective of people aged 80 and over should be researched further with regard to acute care (also in combination with chronic care) and specialties such as pharmacy and dental care.

\section{Conclusion}

This review highlights the fundamental wishes that matter to older people regarding ambulatory healthcare: feeling safe, feeling like a meaningful human being and maintaining control and independence. They interact with several aspects of ambulatory healthcare structures and care relationships that were identified as relevant. In order to achieve patient-centered care for the oldest old, future care models and policies should be developed and evaluated based on these wishes. Furthermore, the relationship between the (fulfillment of) identified wishes on patient-reported experiences and outcomes, such as well-being and satisfaction with care, should be investigated further in order to gain a better understanding of ambulatory care favored by older people.

Supplementary Information The online version contains supplementary material available at https://doi.org/10.1007/s10433-021-00633-7.

Acknowledgements We would like to thank our colleagues and supervisors at the Graduate School GROW for their valuable input into this paper.

Authors' contributions Angélique Herrler involved in conceptualization, methodology, formal analysis, investigation, writing-original draft, writing — review and editing, visualization, and project administration; Helena Kukla involved in formal analysis, investigation, and writing-review and editing; Vera Vennedey involved in conceptualization, methodology, and writing-review and editing; Stephanie Stock involved in conceptualization, methodology, writing-review and editing, and supervision.

Funding Open Access funding enabled and organized by Projekt DEAL. This review was conducted within the Graduate School GROW-Gerontological Research on Well-Being at the University of Cologne, Germany. GROW is funded by the Ministry of Culture and Research of the State of North-Rhine Westphalia, Germany.

Availability of data and material All data and material is available from the authors on request.

\section{Declarations}

Conflicts of interest The authors declare that there are no conflicts of interest.

Open Access This article is licensed under a Creative Commons Attribution 4.0 International License, which permits use, sharing, adaptation, distribution and reproduction in any medium or format, as long as you give appropriate credit to the original author(s) and the source, provide a link to the Creative Commons licence, and indicate if changes were made. The images or other third party material in this article are included in the article's Creative Commons licence, unless indicated otherwise in a credit line to the material. If material is not included in the article's Creative Commons licence and your intended use is not permitted by statutory regulation or exceeds the permitted use, you will need to obtain permission directly from the copyright holder. To view a copy of this licence, visit http://creativecommons.org/licenses/by/4.0/.

\section{References}

Behm L, Ivanoff SD, Ziden L (2013) Preventive home visits and health: experiences among very old people. BMC Public Health 13:378. https://doi.org/10.1186/1471-2458-13-378

Berkelmans PG, Berendsen AJ, Verhaak PF, van der Meer K (2010) Characteristics of general practice care: what do senior citizens value? A qualitative study. BMC Geriatr 10:80. https://doi.org/10. 1186/1471-2318-10-80

Berman P (2000) Organization of ambulatory care provision: a critical determinant of health system performance in developing countries. Bull World Health Organ 78:791-802

Betini RSD, Hirdes JP, Lero DS, Cadell S, Poss J, Heckman G (2017) A longitudinal study looking at and beyond care recipient health as 
a predictor of long term care home admission. BMC Health Serv Res 17:709. https://doi.org/10.1186/s12913-017-2671-8

Bjornsdottir K (2018) 'Holding on to life': an ethnographic study of living well at home in old age. Nurs Inq 25:1. https://doi.org/10. $1111 /$ nin. 12228

Bodenheimer T, Wagner EH, Grumbach K (2002) Improving primary care for patients with chronic illness: the chronic care model, Part 2. JAMA 288:1909-1914. https://doi.org/10.1001/jama.288.15. 1909

Booth A et al (2018) Applying GRADE-CERQual to qualitative evidence synthesis findings-paper 7: understanding the potential impacts of dissemination bias. Implement Sci 13:12. https://doi. org/10.1186/s13012-017-0694-5

Bridges J, Flatley M, Meyer J (2010) Older people's and relatives' experiences in acute care settings: systematic review and synthesis of qualitative studies. Int J Nurs Stud 47:89-107. https://doi.org/ 10.1016/j.ijnurstu.2009.09.009

Claassens L, Widdershoven GA, Van Rhijn SC, Van Nes F, Broese van Groenou MI, Deeg DJ, Huisman M (2014) Perceived control in health care: a conceptual model based on experiences of frail older adults. J Aging Stud 31:159-170. https://doi.org/10.1016/j. jaging.2014.09.008

Collard RM, Boter H, Schoevers RA, Oude Voshaar RC (2012) Prevalence of frailty in community-dwelling older persons: a systematic review. J Am Geriatr Soc 60:1487-1492. https://doi.org/10.1111/j. 1532-5415.2012.04054.x

Costa-Font J, Elvira D, Mascarilla-Miró O (2009) `Ageing in Place'? Exploring elderly people's housing preferences in Spain. Urban Stud 46:295-316. https://doi.org/10.1177/0042098008099356

Dostálová V, Bártová A, Bláhová H, Holmerová I (2020) The needs of older people receiving home care: a scoping review. Aging Clin Exp Res. https://doi.org/10.1007/s40520-020-01505-3

Faeo SE, Bruvik FK, Tranvag O, Husebo BS (2020) Home-dwelling persons with dementia's perception on care support: Qualitative study. Nurs Ethics. https://doi.org/10.1177/0969733019893098

Fried LP, Ferrucci L, Darer J, Williamson JD, Anderson G (2004) Untangling the concepts of disability, frailty, and comorbidity: implications for improved targeting and care. J Gerontol A Biol Sci Med Sci 59:255-263. https://doi.org/10.1093/gerona/59.3. M255

Gonzalez AI et al (2019) Health-related preferences of older patients with multimorbidity: an evidence map. BMJ Open 9:e034485. https://doi.org/10.1136/bmjopen-2019-034485

Gowing A, Dickinson C, Gorman T, Robinson L, Duncan R (2016) Patients' experiences of a multidisciplinary team-led community case management programme: a qualitative study. BMJ Open 6:e012019. https://doi.org/10.1136/bmjopen-2016-012019

Gregory A, Mackintosh S, Kumar S, Grech C (2017) Experiences of health care for older people who need support to live at home: a systematic review of the qualitative literature. Geriatr Nurs 38:315-324. https://doi.org/10.1016/j.gerinurse.2016.12.001

Hajek A et al (2015) Longitudinal predictors of institutionalization in old age. PLoS ONE 10:e0144203-e0144203. https://doi.org/10. 1371/journal.pone. 0144203

Hennink MM, Kaiser BN, Marconi VC (2017) Code saturation versus meaning saturation: how many interviews are enough? Qual Health Res 27:591-608. https://doi.org/10.1177/1049732316 665344

Holm AL, Severinsson E, Walker K (2013) A qualitative systematic review of older persons' perceptions of health, Ill health, and their community health care needs. Nurs Res Pract 2013:672702. https://doi.org/10.1155/2013/672702

Hoogendijk EO et al (2016) Effectiveness of a geriatric care model for frail older adults in primary care: results from a stepped wedge cluster randomized trial. Eur J Intern Med 28:43-51. https://doi. org/10.1016/j.ejim.2015.10.023
Houben PPJ (2001) Changing housing for elderly people and co-ordination issues in Europe. Hous Stud 16:651-673. https://doi.org/ 10.1080/02673030120080107

Inouye SK, Studenski S, Tinetti ME, Kuchel GA (2007) Geriatric syndromes: clinical, research, and policy implications of a core geriatric concept. J Am Geriatr Soc 55:780-791. https://doi.org/ 10.1111/j.1532-5415.2007.01156.x

Jarling A, Rydstrom I, Ernsth-Bravell M, Nystrom M, DalheimEnglund AC (2018) Becoming a guest in your own home: home care in Sweden from the perspective of older people with multimorbidities. Int J Older People Nurs. https://doi.org/10.1111/ opn.12194

John JR, Jani H, Peters K, Agho K, Tannous WK (2020) The effectiveness of patient-centred medical home-based models of care versus standard primary care in chronic disease management: a systematic review and meta-analysis of randomised and nonrandomised controlled trials. Int J Environ Res Public Health. https://doi.org/10.21203/rs.3.rs-35151/v1

King AII, Boyd ML, Dagley L, Raphael DL (2018) Implementation of a gerontology nurse specialist role in primary health care: health professional and older adult perspectives. J Clin Nurs 27:807-818. https://doi.org/10.1111/jocn.14110

Krothe JS (1992) Constructions of elderly people's perceived needs for community-based long-term care. Dissertation, Indiana University School of Nursing

Krothe JS (1997) Giving voice to elderly people: community-based long-term care. Public Health Nurs 14:217-226. https://doi.org/ 10.1111/j.1525-1446.1997.tb00294.x

Leung L (2015) Validity, reliability, and generalizability in qualitative research. J Family Med Prim Care 4:324-327. https://doi. org/10.4103/2249-4863.161306

Lusk JM, Fater K (2013) A concept analysis of patient-centered care. Nurs Forum 48:89-98. https://doi.org/10.1111/nuf.12019

Marengoni A et al (2011) Aging with multimorbidity: a systematic review of the literature. Ageing Res Rev 10:430-439. https:// doi.org/10.1016/j.arr.2011.03.003

Martin-Matthews A, Sims-Gould J (2008) Employers, home support workers and elderly clients: identifying key issues in delivery and receipt of home support. Healthc Q 11:69-75. https://doi. org/10.12927/hcq.2008.20073

Maurer C, Draganescu S, Mayer H, Gattinger H (2019) Attitudes and needs of residents in long-term care facilities regarding physical activity - a systematic review and synthesis of qualitative studies. J Clin Nurs 28:2386-2400. https://doi.org/10.1111/ jocn. 14761

McGilton KS et al (2018) Identifying and understanding the health and social care needs of older adults with multiple chronic conditions and their caregivers: a scoping review. BMC Geriatr 18:231. https://doi.org/10.1186/s12877-018-0925-x

Michel T, Helena Lenardt M, Hautsch Willig M, Maria Alvarez A (2015) From real to ideal - the health (un)care of long-lived elders. Rev Bras Enferm 68:343-349. https://doi.org/10.1590/0034-7167. $2015680304 \mathrm{i}$

Modig S, Kristensson J, Troein M, Brorsson A, Midlöv P (2012) Frail elderly patients' experiences of information on medication. A qualitative study. BMC Geriatr 12:46. https://doi.org/10.1186/ 1471-2318-12-46

Moe A, Hellzen O, Enmarker I (2013) The meaning of receiving help from home nursing care. Nurs Ethics 20:737-747. https://doi.org/ 10.1177/0969733013478959

Moher D, Liberati A, Tetzlaff J, Altman DG (2009) Preferred reporting items for systematic reviews and meta-analyses: the PRISMA statement. PLoS Med 6:e1000097. https://doi.org/10.1371/journ al.pmed. 1000097

Muntinga ME et al (2012) Implementing the chronic care model for frail older adults in the Netherlands: study protocol of ACT (frail 
older adults: care in transition). BMC Geriatr 12:19. https://doi. org/10.1186/1471-2318-12-19

Muntinga ME, van Leeuwen KM, Schellevis FG, Nijpels G, Jansen APD (2015) From concept to content: assessing the implementation fidelity of a chronic care model for frail, older people who live at home. BMC Health Serv Res 15:18. https://doi.org/10. 1186/s12913-014-0662-6

NICE (2012) Quality appraisal checklist-qualitative studies. In: Methods for the development of NICE public health guidance (third edition). National Institute for Health and Care Excellence, London

Nicholson NR (2012) A review of social isolation: an important but underassessed condition in older adults. J Prim Prev 33:137-152. https://doi.org/10.1007/s10935-012-0271-2

Rockwood K, Song X, Mitnitski A (2011) Changes in relative fitness and frailty across the adult lifespan: evidence from the Canadian National Population Health Survey. CMAJ 183:E487-494. https:// doi.org/10.1503/cmaj.101271

Rosero-Bixby L, Dow WH (2009) Surprising SES Gradients in mortality, health, and biomarkers in a Latin American population of adults. J Gerontol B Psychol Sci Soc Sci 64:105-117. https://doi. org/10.1093/geronb/gbn004

Sandberg M, Jakobsson U, Midlov P, Kristensson J (2014) Case management for frail older people-a qualitative study of receivers' and providers' experiences of a complex intervention. BMC Health Serv Res. https://doi.org/10.1186/1472-6963-14-14

Sandelowski M, Barroso J (2007) Handbook for synthesizing qualitative research. Springer, New York

Saunders B et al (2018) Saturation in qualitative research: exploring its conceptualization and operationalization. Qual Quant 52:18931907. https://doi.org/10.1007/s11135-017-0574-8

Scholl I, Zill JM, Härter M, Dirmaier J (2014) An integrative model of patient-centeredness-a systematic review and concept analysis. PLoS ONE 9:e107828. https://doi.org/10.1371/journal.pone. 0107828

Schulman-Green DJ, Naik AD, Bradley EH, McCorkle R, Bogardus ST (2006) Goal setting as a shared decision making strategy among clinicians and their older patients. Patient Educ Couns 63:145151. https://doi.org/10.1016/j.pec.2005.09.010

Soodeen RA, Gregory D, Bond JB (2007) Home care for older couples: "It feels like a security blanket." Qual Health Res 17:1245-1255. https://doi.org/10.1177/1049732307307339

Spoorenberg SLW, Wynia K, Fokkens AS, Slotman K, Kremer HPH, Reijneveld SA (2015) Experiences of community-living older adults receiving integrated care based on the chronic care model: a qualitative study. PLoS ONE 10:1. https://doi.org/10.1371/journ al.pone. 0137803

Street RL, Elwyn G, Epstein RM (2012) Patient preferences and healthcare outcomes: an ecological perspective. Expert Rev Pharmacoecon Outcomes Res 12:167-180. https://doi.org/10.1586/erp.12.3

Thomas J, Harden A (2008) Methods for the thematic synthesis of qualitative research in systematic reviews. BMC Med Res Methodol 8:45. https://doi.org/10.1186/1471-2288-8-45
Tiilikainen E, Hujala A, Kannasoja S, Rissanen S, Närhi K (2019) "They're always in a hurry"-older people's perceptions of access and recognition in health and social care services. Health Soc Care Community 27:1011-1018. https://doi.org/10.1111/hsc.12718

Toien M, Bjork IT, Fagerstrom L (2015) Older users' perspectives on the benefits of preventive home visits. Qual Health Res 25:700 712. https://doi.org/10.1177/1049732314553595

Tong A, Flemming K, McInnes E, Oliver S, Craig J (2012) Enhancing transparency in reporting the synthesis of qualitative research: ENTREQ. BMC Med Res Methodol 12:181. https://doi.org/10. 1186/1471-2288-12-181

Turjamaa R, Hartikainen S, Kangasniemi M, Pietila AM (2014) Living longer at home: a qualitative study of older clients' and practical nurses' perceptions of home care. J Clin Nurs 23:3206-3217. https://doi.org/10.1111/jocn.12569

United Nations (2019) World population prospects 2019: highlights. United Nations, Department of Economic and Social Affairs, Population Division, New York

van Blijswijk SCE et al (2018) Wishes and needs of community-dwelling older persons concerning general practice: a qualitative study. PLoS ONE 13:14. https://doi.org/10.1371/journal.pone.0200614

van den Bussche H, Schoen G, Kolonko T, Hansen H, Wegscheider K, Glaeske G, Koller D (2011) Patterns of ambulatory medical care utilization in elderly patients with special reference to chronic diseases and multimorbidity: results from a claims data based observational study in Germany. BMC Geriatr 11:54. https://doi. org/10.1186/1471-2318-11-54

van Kempen JA, Robben SH, Zuidema SU, Rikkert MG, Melis RJ, Schers HJ (2012) Home visits for frail older people: a qualitative study on the needs and preferences of frail older people and their informal caregivers. Br J Gen Pract 62:554-560. https://doi.org/ 10.3399/bjgp12X653606

Walker R, Ratcliffe J, White A, Visvanathan R (2018) Dementia assessment services: what are the perceptions of older people? Australas J Ageing 37:43-47. https://doi.org/10.1111/ajag.12455

Whittemore R, Chase SK, Mandle CL (2001) Validity in qualitative research. Qual Health Res 11:522-537. https://doi.org/10.1177/ 104973201129119299

World Health Organization (2015a) WHO global strategy on peoplecentred and integrated health services. World Health Organization. https://www.who.int/servicedeliverysafety/areas/peoplecentred-care/global-strategy/en/. Accessed 15 Mar 2021

World Health Organization (2015b) World report on ageing and health. World Health Organization, Geneva

Wiles JL, Leibing A, Guberman N, Reeve J, Allen RES (2012) The meaning of "aging in place" to older people. Gerontologist 52:357-366. https://doi.org/10.1093/geront/gnr098

Publisher's Note Springer Nature remains neutral with regard to jurisdictional claims in published maps and institutional affiliations. 